\title{
Single Layer Graphene and Vertical Graphene as a Promising Candidate for Electrochemical Biosensors
}

\section{BIANCA TINCU ${ }^{1,2 *}$ MARIOARA AVRAM ${ }^{1}$, VASILICA TUCUREANU ${ }^{1}$, CARMEN MIHAILESCU ${ }^{1}$, OANA TUTUNARU ${ }^{1}$, ANDREI AVRAM ${ }^{1}$, ELENA ANGHEL ${ }^{1,2 *}$}

${ }^{1}$ National Institute for Research and Development in Microtechnologies IMT-Bucharest, 126A, Erou Iancu Nicolae Str., 077190, Bucharest, Romania

${ }^{2}$ Politehnica University of Bucharest, Applied Chemistry and Materials Science Department, 1-7 Gheorghe Polizu Str., 011061, Bucharest, Romania

\begin{abstract}
Recently, graphene as a material for sensors has attracted attention due to unique properties, such as: excellent electrical and thermal conductivity, chemical stability, high surface area and Young's modulus 1GPa, very promising for electrochemical applications. Electrochemical sensors based on graphene have been used in many applications, such as: biomolecules, gases or metal ions detection. Here, we report the effect of morphology and orientation of graphene as electrode material with electrochemical method. We investigated the capacitive performance in the case of horizontal and vertical graphene sheets, synthetized by thermal chemical vapor deposition $(C V D)$, respectively plasma enhanced chemical vapor deposition (PECVD). Graphene electrode is used in electrochemical cells with three electrodes as a working electrode. Raman spectroscopy was carried on the graphene films for quality and structure characterization. The working electrode was characterized by scanning electron microscopy (SEM), Raman spectroscopy and electrochemical method.
\end{abstract}

Keywords: Single layer graphene, Graphene Nano-walls, working electrode, chemical vapour deposition, electrochemical method

\section{Introduction}

2D nanomaterials have been employed for biosensing devices development due to their remarkable properties. Nowadays, graphene is the most reported two-dimensional nanomaterials with various applications, extensively investigated as material electrode due to their large specific surface area. Graphene, a single layer of carbon atoms $\mathrm{sp}^{2}$ hybridized, distinguished from another carbon materials by the unique properties, such as: physical: zero-bandgap, electrical: ambipolar electrical field effect, high electrical conductance $\sim 64 \mathrm{mS} \mathrm{cm}$, electrochemical: large potential window, fast electron transfer rate, excellent electrochemical activity, low charge-transfer resistance [1-3]. Graphene has been introduced important advantages in graphene-based devices, such as: mass production, low cost, sensitivity and sensibility, useful for sensors, biosensors, and many more applications. Graphene monoand multilayers has been obtained with different methods including: mechanical exfoliation, reduction of graphene oxide, epitaxial growth, chemical exfoliation and chemical vapor deposition (CVD) [4, 5]. CVD is the most used technique to obtain graphene with high quality and large domains area, chemical stability and excellent electrical conductivity, ideally for electrochemical biosensors. In order to obtain graphene oriented vertically on the substrate, the most commonly used method is plasma enhanced chemical vapor deposition (PECVD). The PECVD method is capable of directly growing graphene nanowalls on various target substrates, thus avoiding the transfer process, which is a complex one. In the presence of plasma, the carbon-containing precursors are dissociated and the high electric field, which is aligned perpendicular to the surface, generates graphene with a special, vertically oriented

*email: bianca.tincu@imt.ro; elena.anghel@imt.ro 
structure [6]. Graphene sheets horizontal and vertical oriented on working electrode affects the electrochemical performance, evidenced by this study. Moreover, the comparison between single layer graphene and vertical graphene is an essential step for applications, so in function of application we can chose the graphene type [7].

In the last 10 years, graphene-based materials-oriented electrochemistry have greatly stimulated research interests. Examples are targeted on graphene-based electrochemical sensing and biosensing, supercapacitor devices, electrocatalysis, electrochemiluminescence, field effect transistors, etc. The graphene- based materials incur long cycle life, good electrical conductivity and chemical stability [8, 9]. One of the first reports of the graphene in electrochemistry emerged in 2009 when Chen and coworkers describe the theoretical critical review of the exciting progress related to graphene from the standpoint of electrochemistry since 2004 [10]. Single layer graphene is reported with a good thermal conductivity of $5000 \mathrm{~W} / \mathrm{mK}$ at room temperature. The reported intrinsic capacitance of single layer graphene was $\sim 21 \mu \mathrm{F} \mathrm{cm} ~^{-2}$; this rate positions the upper limit for electric double-layer (EDL) capacitance for all carbon nanomaterials. Kim and coworkers reported a specific energy density of around $85.6 \mathrm{Wh} / \mathrm{kg}$ at room temperature and $136 \mathrm{Wh} / \mathrm{kg}$ at $80^{\circ} \mathrm{C}$ [11]. For individual graphene have reported a capacitance around $10.9 \mathrm{~F} / \mathrm{g}$ [12]. Sun and coworkers reported a large specific capacitance around $138 \mathrm{~F} / \mathrm{g}$ for multilayered graphene structure in aqueous electrolyte at a scan rate of $10 \mathrm{mv} / \mathrm{S}$ and a specific current of $10 \mathrm{~A} / \mathrm{g}$ [12]. Thus, latest scientifically reports have largely illustrated on the scalability of graphene-based materials through CVD synthesis method [13, 14]. In addition to these graphene-specific properties, the vertical graphene has some unique properties which make it a material with a big potential in many applications. One of the most important feature of the vertical graphene is its vertical orientation on the substrate, which improves the property of mechanical stability. It is considered that each vertical graphene nanosheet represents a self-supported structure with rigid integrity by itself [15]. Another feature of it is its morphology which is non-agglomerated and has high specific surface area. Vertical graphene networks could rich high value of $1100 \mathrm{~m}^{2} \mathrm{~g}^{-1}$ in order to the specific surface area [16]. Moreover, it has exposed, ultra-thin and reactive edges. The thin graphene layers have usually an interlayer spacing between 0.34 and $0.39 \mathrm{~nm}$ [17]. Due to the fact that vertical graphene grow on a conductive surface, the contact resistance between it and substrate is reduced. According to Zheny et al. [18], vertical graphene obtained by PECVD method using the parameters gas mixture $\mathrm{CH}_{4} / \mathrm{C}_{2} \mathrm{H}_{2}$ and temperature $300-800^{\circ} \mathrm{C}$, has following features: surface area $1100-1800 \mathrm{~m}^{2} \mathrm{~g}^{-1}$, pore size less than $1 \mu \mathrm{m}$ and electrical conductivity in range of $10^{2}-10^{3} \mathrm{Sm}^{-1}$. According to Yamada T. et al., in a study from 2017 [19], they found the reflectance of vertically aligned graphene nanosheets less than $0.067 \%$.

In this paper, single layer graphene and vertical graphene was synthetized by Chemical Vapor Deposition and Plasma Enhanced Chemical Vapor Deposition method, and comparatively study by morphological structure with Scanning Electron microscopy, by structural characterization with Raman spectroscopy and electrochemical by Electrochemical Impedance Spectroscopy (EIS). The control of high-quality single layer graphene on substrates will be explored, considering its importance for biosensing applications. Single layer graphene requires the transfer process on a specific substrate essential step for applications, while vertical graphene grow directly on the substrate. Graphene, a bidimensional allotrope of carbon has shown an important impact in the micro technologies area due to its unique properties (mechanical, optical and electrical). The properties of single layer graphene and vertical graphene, on silicon oxide substrate were investigated by: Raman spectroscopy and Scanning electron microscopy (SEM). Electrochemical impedance spectroscopy (EIS) is utilized to study the influence of graphene in conductivity and interfacial charge transfer characteristics.

\section{Materials and methods}

\section{Synthesis of single layer graphene and vertical graphene by CVD and PECVD method}

Graphene materials: single layer graphene and vertical graphene (Figure 1) are growth by Chemical vapor deposition and Plasma enhanced chemical vapor deposition method with Plasma Pro 1000 
equipment (NANOFAB 1000, Oxford Instruments, UK), special equipment for carbon materials processes [20]. Single layer graphene was obtained on copper metal catalyst, with Temperature-CVD at a high temperature: $1080^{\circ} \mathrm{C}$ for $1 \mathrm{~h}$, in presence of a mixture gases: $\mathrm{Ar}, \mathrm{H}_{2}$ and $\mathrm{CH}_{4}$. For applications, graphene is transferred on target substrate, in this paper on $\mathrm{Si} / \mathrm{SiO}_{2}$ by wet chemical method. Polymethyl-methacrylate (PMMA) was spin-coated on the single layer graphene growth on $\mathrm{Cu}$ film. Copper is etched away by chemical etching in a solution of $\mathrm{HCl}-\mathrm{H}_{2} \mathrm{O}_{2}$, graphene is scoop-out with $\mathrm{Si} / \mathrm{SiO}_{2}$ and PMMA was removed in boiling acetone [20-22]. Vertical graphene was obtained directly on silicon oxide substrate using the following parameters: temperature $700^{\circ} \mathrm{C}$, RF power 300 W, pressure 300 mTorr and gas mixture $\mathrm{CH}_{4}-10 \mathrm{sccm}$ and $\mathrm{Ar}-190 \mathrm{sccm}$, time 60 minutes [23].

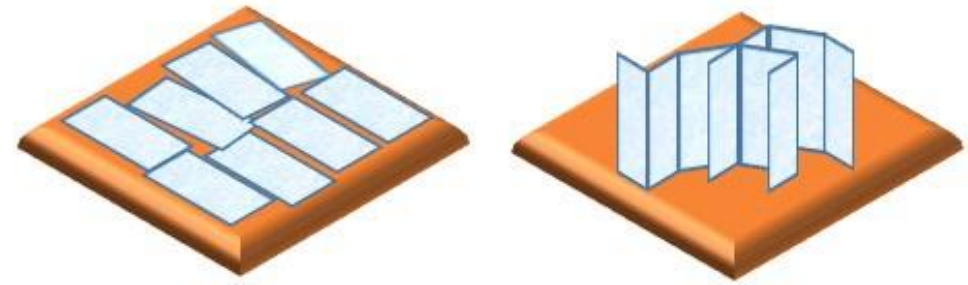

Figure 1. A) Single layer graphene on target substrate and

B) Vertical graphene on growth substrate

Raman spectroscopy was used to evaluate single layer graphene transferred on target substrate and vertical graphene growth on $\mathrm{SiO}_{2}$. Raman spectra have been acquired by using LabRam HR800 Raman spectrometer (Horiba Jobin Yvon, Japan) in setup with a He-Ne laser. For the morphology characterization of the graphene layer grown and transferred on silicon/silicon oxide substrate and vertical graphene grown on silicon/silicon oxide substrate by SEM was performed using with a FEI Nova NanoSEM 630 system (FE-SEM). Electrochemical characterization of the graphene-based materials was performed by the EIS (Electrochemical Impedance Spectroscopy) method using the VoltaLab PGZ100 equipment.

\section{Results and discussions}

First, we evaluate the morphology of single layer graphene transferred on $\mathrm{SiO}_{2}$ substrate and of vertical graphene on $\mathrm{SiO}_{2}$ substrate. SEM was used to investigate the coating of the substrate and uniformity of the graphene layer. SEM micrograph of single layer graphene on $\mathrm{SiO}_{2}$ is shown in Figure 2A), confirming graphene transferred with large area on target substrate. Also, graphene single layer shows the presence of wrinkles on its surface. The SEM micrograph of graphene nanowalls on $\mathrm{SiO}_{2}$ substrate are reported in Figure 2B) where the ridge profiles of the raised walls can be distinguished along with the tendency to grow relatively disorder. SEM images show the presence of graphene and evidence a coverage of a full substrate, and a high quality of graphene growth.

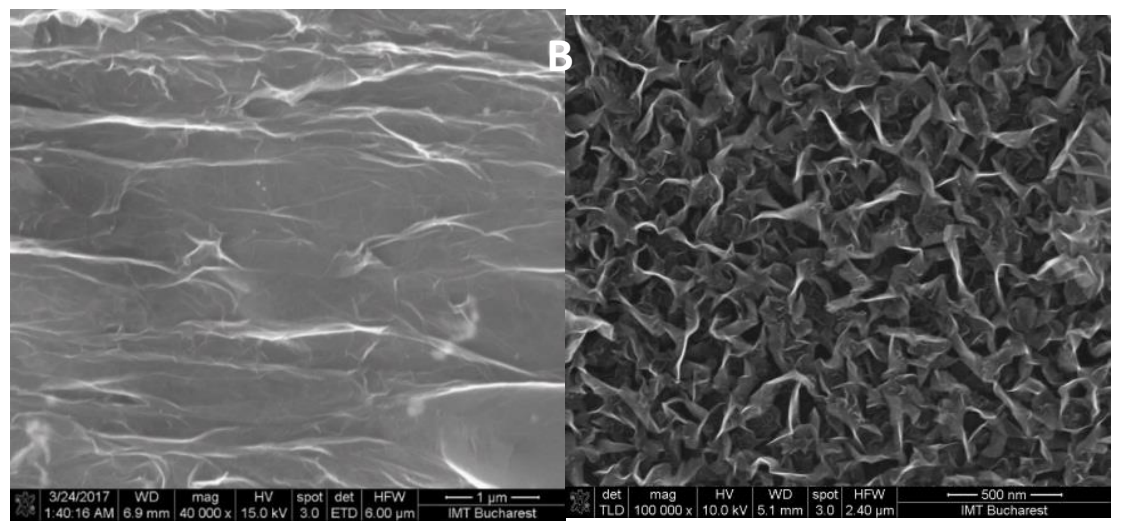

Figure 2. Micrographs of A) single layer graphene and $\mathrm{B}$ ) graphene nanowalls 
Secondly, we evaluate the properties of single layer graphene transferred on $\mathrm{SiO}_{2}$ substrate and vertical graphene on $\mathrm{SiO}_{2}$ substrate using Raman spectroscopy. Raman spectroscopy was performed to determinate the quality of both types of graphene. In Figure 3A) is observed a typical spectrum of single layer graphene by the intensity ratio of $2 \mathrm{D}$ band located at $2680 \mathrm{~cm}^{-1}$ and $\mathrm{G}$ band located at $1580 \mathrm{~cm}^{-1}$ around 1.52. The full width at half maximum (FWHM) of the $2 \mathrm{D}$ band $\left(\approx 36 \mathrm{~cm}^{-1}\right)$ is associated with single layer graphene. The weak D band, specific of defects, located at $1350 \mathrm{~cm}^{-1}$ appear due to transfer process. In figure 3B) with the spectrum of vertical graphene it can be observed how the bands D and G (accompanied by D') are very well outlined in the electronic noise, centered on $1340 \mathrm{~cm}^{-1}$ and $1571 \mathrm{~cm}^{-1}$, while at $2674 \mathrm{~cm}^{-1}$ the very pronounced $2 \mathrm{D}$ band is observed.

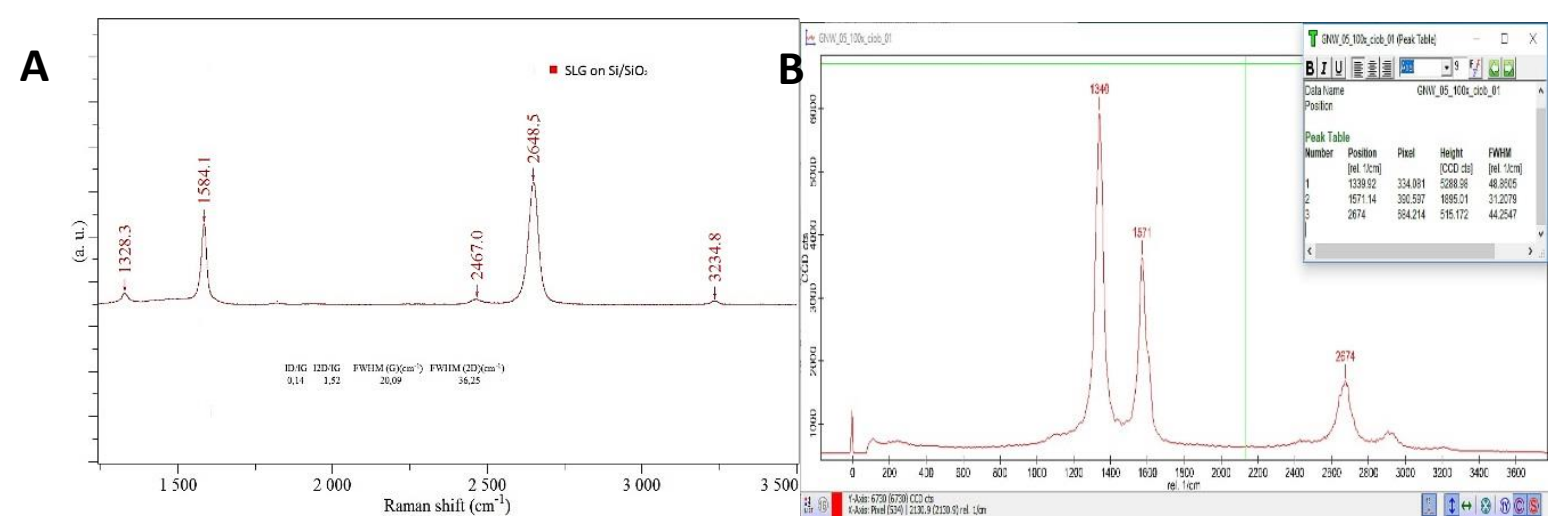

Figure 3. Raman spectrum of A) single layer graphene transferred on $\mathrm{SiO}_{2}$ substrate and $\mathrm{B}$ ) vertical graphene directly grown on $\mathrm{SiO}_{2}$ substrate

Electrical characterization was performed using Electrochemical Impedance Spectroscopy in phosphate buffered saline. For the graphene based working electrode we measured cyclic voltammogram in the electrolyte solution containing the redox mediator $\left[\mathrm{Fe}(\mathrm{CN})_{6}\right]^{3-14-}$. This redox mediator is sensitive to the functional groups present on the surface of the carbon-based electrodes.

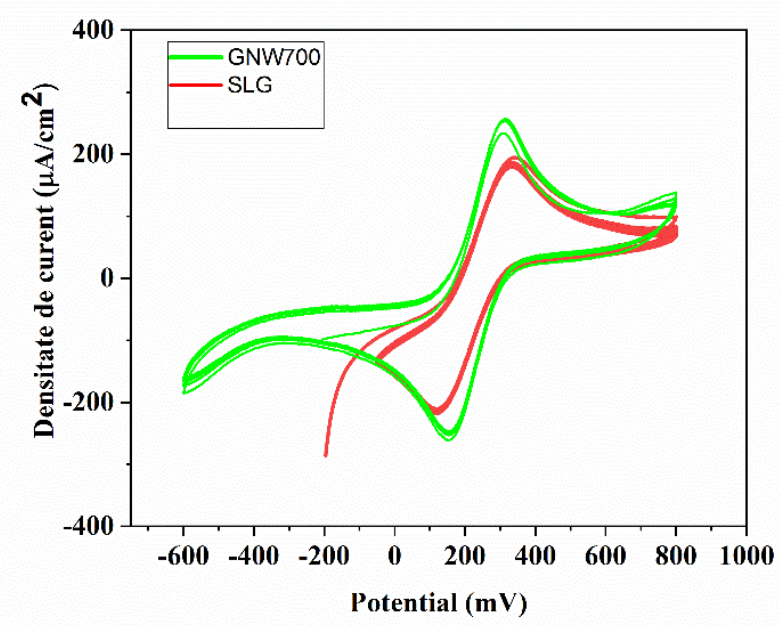

Figure 4. Cyclic voltammogram of single layer graphene transferred on $\mathrm{SiO}_{2}$ substrate and vertical graphene directly grown at $700^{\circ} \mathrm{C}$ on $\mathrm{SiO}_{2}$ substrate

The calculated potential difference $(\Delta \mathrm{E} p=\mathrm{Ea}-\mathrm{Ec})$, measured for the vertical graphene working electrode was $0.216 \mathrm{~V}$ and 0.213 for SLG and both have values comparable to that of the commercial single layer graphene $0.228 \mathrm{~V}$ as it shows in Figure 4 [24]. 


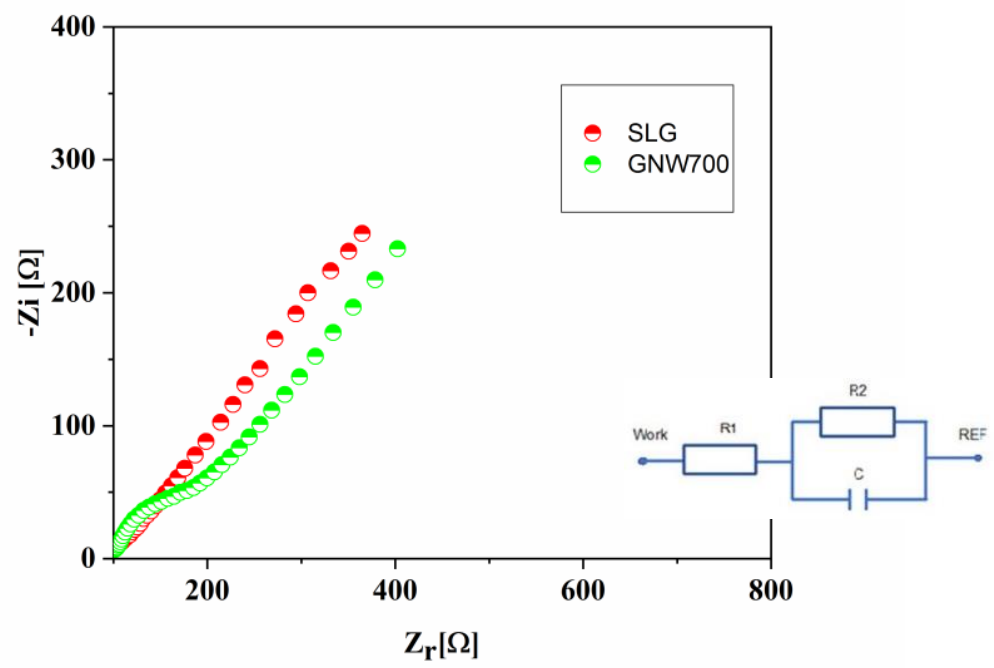

Figure 5. Nyquist diagram of single layer graphene transferred on $\mathrm{SiO}_{2}$ substrate and vertical graphene directly grown at $700^{\circ} \mathrm{C}$ on $\mathrm{SiO}_{2}$ substrate

From the Nyquist (-Zi vs $\mathrm{Zr}$ ) diagram we can calculate the resistance of the working electrode. The resistance of the vertical graphene based working electrode was $244 \Omega \mathrm{xcm}^{2}$ and the conductivity of it was $4 \mathrm{mSxcm}^{-2}$. We used Auto R1R2 Fitt program of the VoltaMaster 4 software to obtain the electrochemical Nyquist parameters from an equivalent circuit with $\mathrm{R}_{1}$ solution resistance, $\mathrm{R}_{2}$ the electron transfer resistance and double capacitance layer $\mathrm{C}$, present in inset of figure 5 . The resistance of SLG was calculate at $153 \Omega \mathrm{xcm}^{2}$ and the conductivity was $7.174 \mathrm{mSxcm}^{-2}$.

\section{Conclusions}

We presented comparatively study of the single layer graphene and vertical graphene based on electrode materials as a platform for optical and bio sensing devices. Graphene sheets horizontal and vertical oriented on working electrode affects the electrochemical performance. It is clear that by the voltammetry signatures which are distinctively different conferring to a function of the different graphene surface morphologies. The sheet resistance of vertical graphene was calculated at $244 \Omega \times \mathrm{cm}^{2}$, but decreases to about $155 \Omega \mathrm{xcm}^{2}$ in the case of single layer graphene transferred on $\mathrm{SiO}_{2}$ substrate. The conductivity of the single layer graphene is $4 \mathrm{mSxcm}^{-2}$ significantly higher than vertical graphene $7.174 \mathrm{mSxcm}^{-2}$. This result demonstrates that in function of specific application the different graphene morphology can be used, based on their electrochemical performance.

Acknowledgements. The work of Bianca Tincu has been funded by the Operational Programme Human Capital of the Ministry of European Funds through the Financial Agreement 51668/09.07.2019, SMIS code 124705. This work was supported by UEFISCDI in the Partnership Framework PN-III-P1-1.2-PCCDI-2017-0214 (Project No. 3PCCDI/2018).

\section{References}

1. WANG, X., GAO, D., LI, M., Li, H., Li, H., WU, X., YANG, B., Sci. Rep., 7, 2017, P. 1-9.

2. YUAN, W., ZHOU, Y., LI, Y., LI, C., PENG, H., ZHANG, J., LIU, Z., DAI, L., Sci. Rep., 3, 2013, P. 3-7.

3. BROWNSON, D.A.C., KAMPOURIS, D.K., BANKS, C.E., Chem. Soc. Rev., 41, 2012, P. 6944 6976.

4. BROWNSON, D.A.C., VAREY, A.S., HUSSAIN, F., HAIGH, S.J., BANKS, C.E., Nanosc., 2014, 6, P. 1607-1621.

5. ChitANU, E., BANCIU, C., SBARCEA G., MARINESCU, V., BARA, A., BARBU, P., Rev. Chim., 69, 2018, 3376. 
6. GUANHUN LIN, YAQING ZHOU, YU WANG, XIN YAN, BAOSHAN WU, FEIFEI HUANG, JUNCHI FU, QIJIN CHENG, DAQIN YUN, Funct. Mat. Let. Vol.11, No.1 (2018), 1850009.

7. MICCOLI, A., RESTANI, P., FLOROIAN, L., TAUS, N., BADEA, M., CIOCA, G., BUNGAU, S., Rev. Chim., 69, 2018, 954

8. PRODANA, M., VOICULET, A., BOJIN, D., IONITA, D., Rev.Chim., 64, 2013, 844.

9. BAHADIR, E.B., SEZGINTURK, M.K., Trends Anal. Chem., 76, 2016, P. 1-14.

10. CHEN, D., TANG, L., LI J., Chem. Soc. Rev., 39, 2010, P. 3157-3180.

11. KIM, J., COTE, L.J., KIM, F., YUAN, W., SHULL, K.R., HUANG, J., J Am Chem Soc. 23, 2010, P. 8180-8186.

12. SUN, Y., WU, Q., SHI, G., Energ Environ Sci. 4, 2011, P. 1113.

13. STOLLER, M.D., RUOFF, R.S., Energ Environ Sci. 9, 2010, P. 1294.

14. LEMINE, A.S., ZAGHO, M., ALtAHTAMOUNI, T., BENSALAH, N., Int J Energy Res. 2018, P. $1-17$.

15. WU, Y. H., QIAO, P. W., CHONG, T. C., SHEN, Z. X., Adv. Mat., 14(1), 64-67 (2002).

16. MILLER, J. R., OUTLAW, R. A., HOLLOWAY, B. C., Science, 329(5999), 1637-1639(2010).

17. BO, Z., YANG, Y., CHEN, J., YU, K., YAN, J., CEN, K., Nanoscale, 5(12), 5180-5204 (2013).

18. ZHENYU ZHANG, CHUN-SING LEE, WENJUN ZHANG, Adv. Eng. Mat., 7, 1700678 (2017).

19. YAMADA T., HISA M., HASEGAWA, M., MRS Advances, 2(02), 77-82 (2017).

20. TINCU, B., DEMETRESCU, I., AVRAM, A., TUCUREANU. V., MATEI, A., TUTUNARU, O., BURINARU, T., COMANESCU, F., VOITINCU, C., AVRAM, M., Diam. Relat. Mater. 98, 2019, 107510.

21. TinCU, B., AVRAM, A., AVRAM, M., TUCUREANU, V., MATEI, A., MARCUleSCU, C., BURINARU, T., COMANESCU, F., MIHALACHE, I., POPESCU, M.C., DEMETRESCU, I., AIP Conf. Proc. 2071, 2019.

22. TinCU, B., AVRAM, A., AVRAM, M., TUCUREANU, V., MATEI, A., MARCUlESCU, C., BURINARU, T., COMANESCU, F., POPESCU, M., AVRAM, M., IOP Conf. Ser.: Mater. Sci. Eng. 485012027.

23. ANGHEL, E., SIMIONESCU, O., PACHIU, C., TUTUNARU, O., MIHAILESCU, C., AVRAM, A., CAS Conf. Proc., 2019.

24. MICHAEL, K. H, VERBERCK, B., Phys. Rev. B 78, 2008.

Manuscript received: 16.12 .2019 